\title{
Cocaine Administered into the Medial Prefrontal Cortex Reinstates Cocaine-Seeking Behavior by Increasing AMPA Receptor-Mediated Glutamate Transmission in the Nucleus Accumbens
}

\author{
W.-K. Park, ${ }^{1}$ A. A. Bari, ${ }^{1}$ A. R. Jey, ${ }^{1}$ S. M. Anderson, ${ }^{1}$ R. D. Spealman, ${ }^{2}$ J. K. Rowlett, ${ }^{2}$ and R. C. Pierce ${ }^{1}$ \\ ${ }^{1}$ Laboratory of Neuropsychopharmacology, Departments of Pharmacology and Psychiatry, Boston University School of \\ Medicine, Boston, Massachusetts 02118, and 2Harvard Medical School, New England Regional Primate Research \\ Center, Southborough, Massachusetts 01772
}

One of the major determinants of reinstatement to cocaine use among human addicts is acute reexposure to the drug, which often precipitates cocaine craving and relapse. We used an animal model of cocaine relapse to determine the role of the glutamatergic pathway from the medial prefrontal cortex (mPFC) to the nucleus accumbens in the reinstatement of cocaine-seeking behavior after a cocaine priming injection. Rats were trained to self-administer cocaine intravenously on a second order schedule. Responding was extinguished subsequently by substituting saline for cocaine. During subsequent reinstatement sessions, drug-seeking behavior was assessed after noncontingent priming injections. Results indicated that reinstatement induced by a systemic cocaine injection was blocked by intra-mPFC administration of the dopamine antagonist flupenthixol. Consistent with this finding, administration of cocaine directly into the mPFC reinstated cocaine-seeking behavior. Administration of cocaine into the nucleus accumbens also reinstated drug seeking, whereas microinjection of cocaine into the neostriatum or lateral septum did not. Reinstatement of cocaine seeking induced by intra-mPFC cocaine was blocked by administration of the AMPA receptor antagonist CNQX into the nucleus accumbens. Administration of the NMDA receptor antagonist AP-5 into the nucleus accumbens had variable effects on reinstatement induced by intra-mPFC cocaine in that AP-5 had no effect in some animals but augmented reinstatement in others. Subsequent experiments showed that intra-accumbal microinjection of AP-5 alone dose-dependently reinstated cocaine seeking. These data indicate that the glutamatergic pathway from the mPFC to the nucleus accumbens plays an important role in cocaine priming-induced reinstatement of drug seeking. Moreover, the present results demonstrate that AMPA and NMDA receptors in the nucleus accumbens have opposing roles in the reinstatement of cocaine-seeking behavior.

Key words: relapse; nucleus accumbens; medial prefrontal cortex; cocaine; glutamate; dopamine; AMPA; NMDA; CNQX; $A P-5$
The relapse rate among human addicts after cocaine detoxification is discouragingly high (Carroll et al., 1994). Although many factors contribute to the reinstatement of cocaine-seeking behavior, it is clear that acute reexposure to cocaine is a major determinant of relapse (Jaffe et al., 1989). Relapse of cocaine selfadministration among human addicts is modeled in rats and monkeys by administering priming drug injections to animals in which cocaine self-administration behavior has been extinguished. Using this paradigm, a priming injection of cocaine results in robust reinstatement of cocaine-seeking behavior (Gerber and Stretch, 1975; de Wit and Stewart, 1981; Wise et al., 1990;

Received July 23, 2001; revised Jan. 14, 2002; accepted Jan. 16, 2002.

This work was supported by Grant RO1 DA12171 from the National Institutes of Health (R.C.P., W.-K.P., A.R.J., S.M.A., A.A.B.), a National Alliance for Research on Schizophrenia and Depression Young Investigator Award (R.C.P.), and a New Investigator Award from the Harcourt General Charitable Foundation (R.C.P.). A.A.B. was partially supported by a National Research Service Award from the National Institutes of Health (F30 DA14205). W.-K.P. was partially supported by a grant from the Korea Science and Engineering Foundation (KOSEF, 1999). J.K.R. and R.D.S. were supported by grants from the National Institutes of Health (R01 DA00499, R01 DA11054, and P51 RR00168). We thank Audrey Pierce for technical assistance and comments on an earlier version of this manuscript.

Correspondence should be addressed to Chris Pierce, Department of Pharmacology, R-612, Boston University School of Medicine, 715 Albany Street, Boston, MA 02118. E-mail: rcpierce@acs.bu.edu.

W.-K. Park's present address: Pharmaceutical Screening Research Team, Korea Research Institute of Chemical Technology, 100 Jang-Dong, Yusong-Gu, Daejon 305-606, Korea.

Copyright (ㄷ) 2002 Society for Neuroscience $\quad 0270-6474 / 02 / 222916-10 \$ 15.00 / 0$
Comer et al., 1993; Self et al., 1996; Spealman et al., 1999). Given the important role of the mesolimbic dopamine system in cocaine reinforcement (Wise et al., 1995; Mello and Negus, 1996; Koob et al., 1998; Spealman et al., 1999), it is not surprising that increased dopamine transmission results in the reinstatement of cocaineseeking behavior. In this regard, administration of D2-like dopamine receptor agonists reinstated cocaine seeking (Self et al., 1996; De Vries et al., 1999, 2002; Spealman et al., 1999; Khroyan et al., 2000). In addition, intra-accumbal administration of dopamine (Cornish and Kalivas, 2000) or a protein kinase A (PKA) inhibitor (Self et al., 1998) reinstated cocaine seeking in rats. Collectively, these data indicate that increased dopamine transmission plays a critical role in triggering the reinstatement of cocaine-seeking behavior.

In addition to dopaminergic inputs from the ventral tegmental area (VTA), the nucleus accumbens receives glutamatergic afferents from several cortical nuclei, including the medial prefrontal cortex (mPFC) (Phillipson and Griffiths, 1985; Berendse et al., 1992; Brog et al., 1993; Wright and Groenewegen, 1995), a structure that plays an important role in both the maintenance of cocaine self-administration behavior (Goeders and Smith, 1983; Martin-Iverson et al., 1986; McGregor and Roberts, 1995) and the reinstatement of cocaine-seeking behavior (McFarland and Kalivas, 2001). Therefore, it seems likely that the glutamatergic $\mathrm{mPFC}$-accumbal pathway may play a role in the reinstatement of cocaine-seeking behavior. In support of this idea, alterations in 
accumbal glutamate transmission have been linked to the reinstatement of cocaine-seeking behavior. Administration of an AMPA agonist into the nucleus accumbens reinstated cocaine seeking in rats, and intra-accumbal administration of an AMPA antagonist impaired reinstatement induced by a systemic cocaine priming injection (Cornish et al., 1999; Cornish and Kalivas, 2000). Taken together, these results indicate that enhanced accumbal glutamatergic transmission acting primarily through AMPA receptors is sufficient to reinstate cocaine-seeking behavior.

The focus of this report is the examination of the potential role of the glutamatergic projection from the mPFC to the nucleus accumbens in the reinstatement of cocaine-seeking behavior. Our results indicate that a priming injection of cocaine administered into the $\mathrm{mPFC}$ reinstated cocaine-seeking behavior and that this effect was blocked by intra-accumbal microinjection of an AMPA antagonist. In contrast, administration of an NMDA antagonist into the nucleus accumbens promoted cocaine-seeking behavior.

\section{MATERIALS AND METHODS}

Animals and housing. Male Sprague Dawley rats (Rattus norvegicus) weighing 250-300 gm were obtained from Taconic Laboratories (Germantown, NY). Animals were housed individually with food and water available ad libitum. A $12 \mathrm{hr}$ light/dark cycle was used with the lights on at 7:00 A.M. All experimental procedures were performed during the light cycle. All experimental protocols were consistent with the guidelines issued by the National Institutes of Health and were approved by the Boston University School of Medicine Institutional Animal Care and Use Committee.

Materials. All experiments used Med-Associates (East Fairfield, VT) operant chambers equipped with response levers, stimulus lights, food pellet dispensers, and pumps for injecting drugs intravenously. The operant chambers were enclosed within ventilated, sound-attenuating chambers.

Food training. All rats assigned to the reinstatement experiments initially were trained to self-administer food pellets. The animals were restricted to two $2.25 \mathrm{gm}$ food pellets (Ralston Purina, St. Louis, MO) per day for $3 \mathrm{~d}$ and then placed into operant chambers where every lever press resulted in the administration of a food pellet $(45 \mathrm{mg}$ Noyes Precision food pellets; PJ Noyes, Lancaster, NH). Once stable responding was obtained using this continuous reinforcement (CRF) schedule, the rats were switched to a five-response, fixed-ratio (FR) schedule of reinforcement. After at least 7 total days of food training, surgery was performed. Rats in the reinstatement experiments had ad libitum access to food in the home cage after surgery and for the remainder of the study.

Surgery. Before surgery, the rats were anesthetized with $80 \mathrm{mg} / \mathrm{kg}$ ketamine and $12 \mathrm{mg} / \mathrm{kg}$ xylazine. An indwelling SILASTIC catheter was placed into the right jugular vein and sutured in place. After catheter implantation, the rat was mounted in a stereotaxic apparatus. The catheter was routed to a screw-on mount (Plastics One, Roanoke, VA) and cemented to the skull. Catheters were flushed daily with $0.3 \mathrm{ml}$ of an antibiotic (Timentin, $0.93 \mathrm{mg} / \mathrm{ml}$ ) dissolved in heparinized saline. The catheters were sealed with plastic obturators when not in use.

During surgery, guide cannulas (26 gauge; $14 \mathrm{~mm}$ for nucleus accumbens, neostriatum, and lateral septum, $10 \mathrm{~mm}$ for mPFC) for microinjections also were implanted bilaterally $2 \mathrm{~mm}$ dorsal to the nucleus accumbens, neostriatum, lateral septum, and/or mPFC and cemented in place by affixing dental acrylic to stainless steel screws secured in the skull. The coordinates for the placement of the guide cannulas, relative to bregma according to the atlas of Paxinos and Watson (1997), were as follows: nucleus accumbens: $+1.0 \mathrm{~mm}$ anteroposterior $(\mathrm{A} / \mathrm{P}), \pm 0.8 \mathrm{~mm}$ mediolateral (M/L), $-5.0 \mathrm{~mm}$ dorsoventral (D/V); $\mathrm{mPFC}:+2.5 \mathrm{~mm} \mathrm{~A} / \mathrm{P}, \pm 0.5 \mathrm{~mm}$ $\mathrm{M} / \mathrm{L},-2.0 \mathrm{~mm} \mathrm{D} / \mathrm{V}$; neostriatum: $+1.0 \mathrm{~A} / \mathrm{P}, \pm 3.0 \mathrm{~mm} \mathrm{M} / \mathrm{L},-3.0 \mathrm{~mm}$ $\mathrm{D} / \mathrm{V}$; lateral septum: $+1.0 \mathrm{~mm} \mathrm{~A} / \mathrm{P}, \pm 0.8 \mathrm{~mm} \mathrm{M} / \mathrm{L},-3.0 \mathrm{~mm} \mathrm{D} / \mathrm{V}$.

Self-administration, extinction, and reinstatement. The paradigm described below is a modification of the methods described by Spealman and colleagues (Spealman et al., 1999; Khroyan et al., 2000). After a $7 \mathrm{~d}$ recovery period from surgery, the rats were placed in operant chambers and allowed to lever press for intravenous cocaine infusions $(0.25 \mathrm{mg}$ cocaine in $59 \mu \mathrm{l}$ saline, infused over $5 \mathrm{sec}$ ). Rats were trained initially using a CRF schedule with each daily self-administration session initiated by an intravenous priming injection of cocaine $(0.25 \mathrm{mg})$. The rats were limited to a maximum of 10 cocaine infusions per selfadministration session. When the animals achieved stable responding with the CRF schedule (i.e., $<15 \%$ variation in response rates over 3 consecutive days), they were switched to a second-order schedule of reinforcement.

Cocaine self-administration behavior was maintained using a fixed interval 10(fixed ratio 10) [FI10(FR10)] second-order schedule of reinforcement. With this schedule a red light above the active lever was illuminated for $5 \mathrm{sec}$ after every 10th lever press during the $10 \mathrm{~min}$ FI. Completion of the first FR after the FI expired resulted in an intravenous infusion of cocaine and the illumination of the red light over the active lever for $5 \mathrm{sec}$. A $60 \mathrm{sec}$ timeout period during which responses had no scheduled consequences followed each cocaine infusion. If the FR requirement was not completed within 5 min after the expiration of the FI, the component ended automatically without a cocaine infusion and was followed by a $60 \mathrm{sec}$ timeout. Each daily session ended after the completion of 10 cycles of the second-order schedule.

Once stable responding with the FI10(FR10) schedule was achieved, drug-seeking behavior was extinguished by replacing cocaine with saline and omitting the light stimulus. Daily extinction sessions were conducted until responding was consistently $<10 \%$ of the response rate maintained by cocaine self-administration.

After the extinction phase, priming-induced reinstatement of drugseeking behavior was assessed. One of a range of doses of each drug or its vehicle was administered intraperitoneally (intra-mPFC, intraaccumbal, intra-neostriatal, or intra-lateral septal) noncontingently immediately before each reinstatement session. During each reinstatement session, the FI10(FR10) schedule was used; however, completion of the response requirements for each component resulted in infusion of saline rather than cocaine. The stimulus light was reactivated during the reinstatement phase; the red light over the active lever was illuminated for 5 sec after every 10th lever press. Each reinstatement session was followed by one or more extinction sessions until responding was $<10 \%$ of the response rate maintained by cocaine self-administration. In our hands, these procedures were found to produce robust, maximal reinstatement of drug seeking in rats.

During the reinstatement phase, the ability of cocaine priming injections to reinstate cocaine seeking was examined. Cocaine or its vehicle $(0.9 \%$ saline $)$ was either administered intraperitoneally $(5,10$, or 20 $\mathrm{mg} / \mathrm{kg})$ or microinjected bilaterally into the mPFC $(25,50$, or $100 \mu \mathrm{g} / 0.5$ $\mu \mathrm{l}$ per infusion), nucleus accumbens $(25,50$, or $100 \mu \mathrm{g} / 0.5 \mu \mathrm{l}$ per infusion), neostriatum $(100 \mu \mathrm{g} / 0.5 \mu \mathrm{l}$ per infusion $)$, or lateral septum $(100 \mu \mathrm{g} / 0.5 \mu \mathrm{l}$ per infusion) immediately before the reinstatement session. The effect of intra-mPFC administration of the dopamine receptor antagonist flupenthixol (10 or $30 \mu \mathrm{g} / 0.5 \mu \mathrm{l}$ per infusion) on reinstatement induced by cocaine $(10 \mathrm{mg} / \mathrm{kg}$, i.p.) was assessed. Flupenthixol or its vehicle $(0.9 \%$ saline) was administered immediately before the systemic injection of cocaine just before the reinstatement session. The ability of the local anesthetic lidocaine or the indirect dopamine agonist amphetamine to reinstate cocaine seeking also was assessed. Lidocaine $(100 \mu \mathrm{g} / 0.5 \mu \mathrm{l})$, amphetamine $(50 \mu \mathrm{g} / 0.5 \mu \mathrm{l})$, or their vehicle $(0.9 \%$ saline) was microinjected bilaterally into the mPFC immediately before the reinstatement session. The administration of the various doses of cocaine, lidocaine, amphetamine, flupenthixol, or saline was counterbalanced across reinstatement sessions.

Additional experiments assessed the effect of glutamate antagonists administered into the nucleus accumbens on priming of drug-seeking behavior induced by intra-mPFC cocaine $(100 \mu \mathrm{g} / 0.5 \mu \mathrm{l}$ per infusion). Thus, the AMPA antagonist CNQX $(0.03$ and $0.3 \mu \mathrm{g} / 0.5 \mu \mathrm{l}$ per infusion), the NMDA antagonist AP-5 $(3 \mu \mathrm{g} / 0.5 \mu \mathrm{l}$ per infusion), or their vehicle (1\% DMSO or $0.9 \%$ saline, respectively) was microinjected bilaterally into the nucleus accumbens 5 min before an intra-mPFC microinjection of cocaine ( $100 \mu \mathrm{g} / 0.5 \mu \mathrm{l}$ per infusion $)$. The animals were placed in the operant chambers immediately after the cocaine microinjection. The administration of the antagonists as well as vehicle was counterbalanced across reinstatement sessions. The effect of intraaccumbal administration of AP-5 ( 3 and $30 \mu \mathrm{g} / 0.5 \mu \mathrm{l}$ per inf usion) alone on cocaine seeking also was assessed. The doses of CNQX (Cornish and Kalivas, 2000) and AP-5 (Pulvirenti et al., 1994; Cornish et al., 1999) were chosen on the basis of previous research as well as preliminary studies from our laboratory that indicated effective receptor antagonism after intra-accumbal administration without significant suppression of operant behavior. 
Operant responding maintained by food. Nonspecific effects on operant responding by the glutamate and dopamine antagonists used in the reinstatement experiments described above were evaluated by assessing the effect of these drugs on food-reinforced responding. Rats were trained initially to press a lever under a CRF schedule of food delivery in daily $1 \mathrm{hr}$ sessions. The animals were food restricted as described above for the duration of these experiments. Once stable responding was obtained using the CRF schedule, the rats were switched to an FR5 schedule of reinforcement. When stable responding maintained by food reinforcement using the FR5 schedule was achieved, the effect of CNQX $(0.3 \mu \mathrm{g} / 0.5 \mu \mathrm{l}$ per infusion), AP-5 (3.0 or $30.0 \mu \mathrm{g} / 0.5 \mu \mathrm{l}$ per inf usion), or their vehicles (1\% DMSO or $0.9 \%$ saline, respectively) was assessed by microinjecting these compounds separately into the nucleus accumbens immediately before food self-administration. The effect of intra-mPFC administration of flupenthixol $(30 \mu \mathrm{g} / 0.5 \mu \mathrm{l}$ per side) or its vehicle $(0.9 \%$ saline) on food-reinforced operant responding also was assessed. At least $2 \mathrm{~d}$ of stable responding for food reinforcement separated each session in which a microinjection was performed. The administration of the antagonists as well as their vehicle was counterbalanced across operant sessions.

Microinjection procedures. The obturators were removed from the microinjection guide cannulas and replaced by injection needles (33 gauge stainless steel) that extended $2 \mathrm{~mm}$ below the end of the guide cannulas into the structure of interest. Bilateral infusions were made over $120 \mathrm{sec}$ in a volume of $0.5 \mu \mathrm{l}$ per side. The injection needles were left in place for $60 \mathrm{sec}$ (to allow the compound to diffuse away from the tips of the needles) and then removed.

Verification of cannula placements. After the completion of all microinjection experiments, the animals were overdosed with pentobarbital $(100 \mathrm{mg} / \mathrm{kg}$, i.p.) and perfused intracardially with $0.9 \%$ saline followed by $10 \%$ formalin. The brain was removed, and coronal sections $(100 \mu \mathrm{m})$ were taken at the level of the nucleus accumbens-neostriatum-septum and/or mPFC with a Vibratome (Technical Products International, St. Louis, MO). The sections were mounted on gelatin-coated slides and stained with Cresyl violet. An individual unaware of the animals' behavioral response determined cannula placements as well as potential drugor cannula-induced neuronal damage.

Experimental design and data analysis. In most experiments, each subject received all test and control conditions. In most cases, all doses of two drugs (e.g., CNQX and AP-5) plus vehicle were administered to a single animal across a succession of reinstatement sessions. The maximum number of microinjections per animal was limited to six. This design, in which each subject serves as its own control, permits meaningful results to be obtained with fewer animals than would be required using other designs. The time course data were analyzed with mixedfactors ANOVAs, with repeated measures over component. The component five data were analyzed with one-way ANOVAs. Pairwise comparisons for all ANOVAs were made using Tukey's honestly significant difference (HSD).

Drugs. Cocaine was a gift from the National Institute of Drug Abuse. CNQX, AP-5, and flupenthixol were purchased from Sigma/RBI (St. Louis, MO). All drugs were dissolved in sterile saline except CNQX, which required a $1 \%$ DMSO vehicle.

\section{RESULTS}

\section{Reinstatement of drug seeking induced by systemic cocaine is blocked by intra-mPFC administration of a dopamine antagonist}

The data shown in Figure $1 A$ demonstrate that systemic priming injections of cocaine dose-dependently reinstate cocaine-seeking behavior in rats. The data summarized in Figure $1 A$ depict the response rate (lever presses per minute) during the fifth component of the FI10(FR10) second-order schedule of reinforcement (i.e., the peak behavioral response) for the last selfadministration and extinction sessions as well as the reinstatement phase of the experiment. During the reinstatement phase, the ability of saline and 5,10 , and $20 \mathrm{mg} / \mathrm{kg}$ cocaine to reinstate cocaine-seeking behavior was assessed. The reinstatement data were analyzed with a one-way ANOVA, which revealed a significant main effect of treatment $\left(F_{(3,33)}=19.8 ; p<0.0001\right)$. Subsequent pairwise analyses (Tukey's HSD) showed that the re-
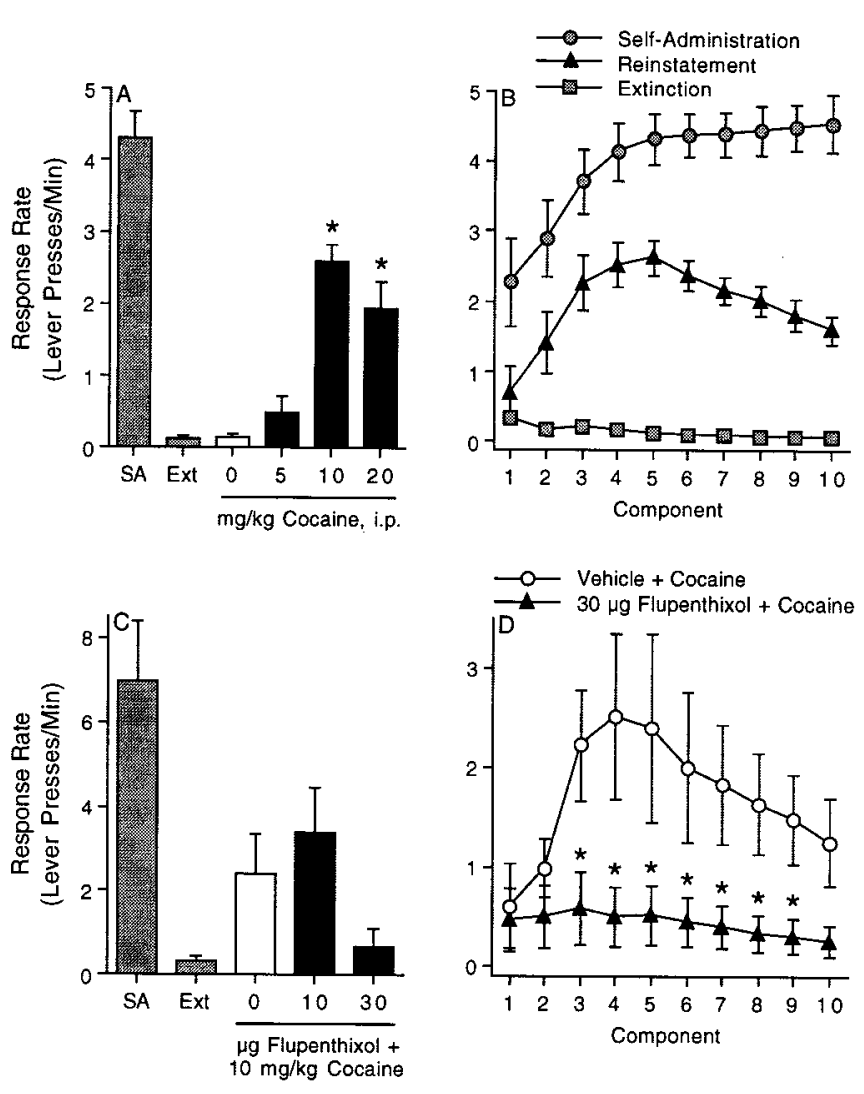

Figure 1. Reinstatement of drug seeking induced by a systemic priming injection of cocaine is blocked by intra-mPFC administration of a dopamine antagonist. The data summarized in $A$ and $C$ depict the response rate (Lever presses/Min) during the fifth component of the FI10(FR10) second-order schedule of reinforcement for the last self-administration $(S A)$ and extinction (Ext) sessions as well as the reinstatement phase of the experiment. These results indicate that systemic cocaine dosedependently reinstates drug seeking $(A)$ and that reinstatement induced by $10 \mathrm{mg} / \mathrm{kg}$ cocaine is dose-dependently inhibited by the intra-mPFC administration of the dopamine antagonist flupenthixol $(C)$. The asterisks in $A$ represent significant differences from saline (Tukey's HSD). The response rate during each of the 10 components of the second-order schedule for self-administration, extinction, and reinstatement after a priming injection of cocaine $(10 \mathrm{mg} / \mathrm{kg}$, i.p. $)$ are shown in $B$. The response rate during each of the 10 components of the second-order schedule for the vehicle + cocaine and $30 \mu \mathrm{g}$ flupenthixol + cocaine treatments are shown in $D$. The error bars indicate \pm SEM. The asterisks in $D$ represent a significant difference from the vehicle + cocaine group at that component (Tukey's HSD). Note that the response rate in the $30 \mu \mathrm{g}$ flupenthixol + cocaine treatment was significantly different from the vehicle + cocaine group during components 3-9. There were five to nine animals per treatment.

sponse rate produced by 10 and $20 \mathrm{mg} / \mathrm{kg}$ cocaine was significantly different from the saline vehicle. The response rates during each of the 10 components of the second-order schedule for self-administration, extinction, and reinstatement after 10 $\mathrm{mg} / \mathrm{kg}$ cocaine (intraperitoneally) are shown in Figure $1 B$. There were 9-10 animals per treatment.

The data summarized in Figure $1 C$ demonstrate that intramPFC administration of the dopamine antagonist flupenthixol dose-dependently impaired drug seeking induced by a systemic injection of $10 \mathrm{mg} / \mathrm{kg}$ cocaine. The data in Figure $1 C$ depict the response rate (lever presses per minute) during the fifth component of the FI10(FR10) second-order schedule of reinforcement for the last self-administration and extinction sessions as well as 
the reinstatement phase of the experiment. During the reinstatement phase, animals were administered saline or 10 or $30 \mu \mathrm{g}$ flupenthixol into the mPFC before a priming injection of cocaine $(10 \mathrm{mg} / \mathrm{kg}$, i.p.). The response rate during each of the $10 \mathrm{com}-$ ponents of the second-order schedule in the vehicle (saline) and $30 \mu \mathrm{g}$ flupenthixol treatments during the reinstatement phase are shown in Figure $1 D$. The reinstatement data from Figure $1 D$ were analyzed with a mixed factors ANOVA with repeated measures over time. This analysis revealed a marginally significant main effect of treatment $\left(F_{(1,8)}=3.84 ; p<0.086\right)$ and a significant main effect of time $\left(F_{(9,72)}=3.07 ; p<0.004\right)$. Although there was no significant interaction between treatment and time, subsequent pairwise analyses (Tukey's HSD) nonetheless showed that the response rate in the vehicle plus cocaine treatment was significantly different from the $30 \mu \mathrm{g}$ flupenthixol plus cocaine treatment during components 3-9. There were five to six animals per treatment.

The fifth component of the second-order schedule represents the peak response of reinstatement induced by intraperitoneal intra-mPFC or intra-accumbal cocaine, which is the rationale for the presentation of the fifth component in this and all subsequent figures.

\section{Reinstatement of drug seeking by cocaine administered into the mPFC or nucleus accumbens but not the neostriatum or lateral septum}

The data summarized in Figure 2 depict the response rate (lever presses per minute) during the fifth component of the FI10(FR10) second-order schedule of reinforcement for the last self-administration and extinction sessions as well as the administration of cocaine directly into the mPFC (Fig. $2 A$ ), nucleus accumbens (Fig. 2B), neostriatum (Fig. $2 C$ ), or lateral septum (Fig. 2D) during the reinstatement phases of these experiments. The reinstatement data shown in Figure 2, $A$ and $B$, were analyzed with separate one-way ANOVAs. The results of these analyses revealed significant main effects of treatment when cocaine was microinjected into the $\operatorname{mPFC}\left(F_{(3,21)}=8.69 ; p<\right.$ $0.0006)$ or nucleus accumbens $\left(F_{(3,21)}=4.87 ; p<0.0099\right)$. Pairwise analyses (Tukey's HSD) showed that $100 \mu \mathrm{g}$ of cocaine microinjected into the mPFC or nucleus accumbens significantly increased the response rate during the fifth component of the second-order schedule. In contrast, paired $t$ tests showed no difference between the microinjection of vehicle or $100 \mu \mathrm{g} \mathrm{co-}$ caine into the neostriatum $\left(t_{(4)}=0.59 ; p<0.58\right)$ or lateral septum $\left(t_{(3)}=0.32 ; p<0.77\right)$ during the reinstatement phase (Fig. 2, $C$ and $D$, respectively). There were $4-10$ rats per treatment. The time course of the reinstatement of drug seeking after intraaccumbal cocaine was similar to intra-mPFC or intraperitoneal cocaine administration. Animals that received cocaine microinjections into the neostriatum or lateral septum had low rates of responding during all 10 components of the reinstatement session.

\section{Reinstatement of drug seeking by intra-mPFC amphetamine but not intra-mPFC lidocaine}

We also assessed the ability of intra-mPFC administration of the indirect dopamine agonist amphetamine (which, like cocaine, increases the extracellular concentration of monoamines but does not share cocaine's local anesthetic property) and the local anesthetic lidocaine to reinstate cocaine seeking. The data summarized in Figure $3 A$ depict the response rate (lever presses per minute) during the fifth component of the FI10(FR10) secondorder schedule of reinforcement for the last self-administration
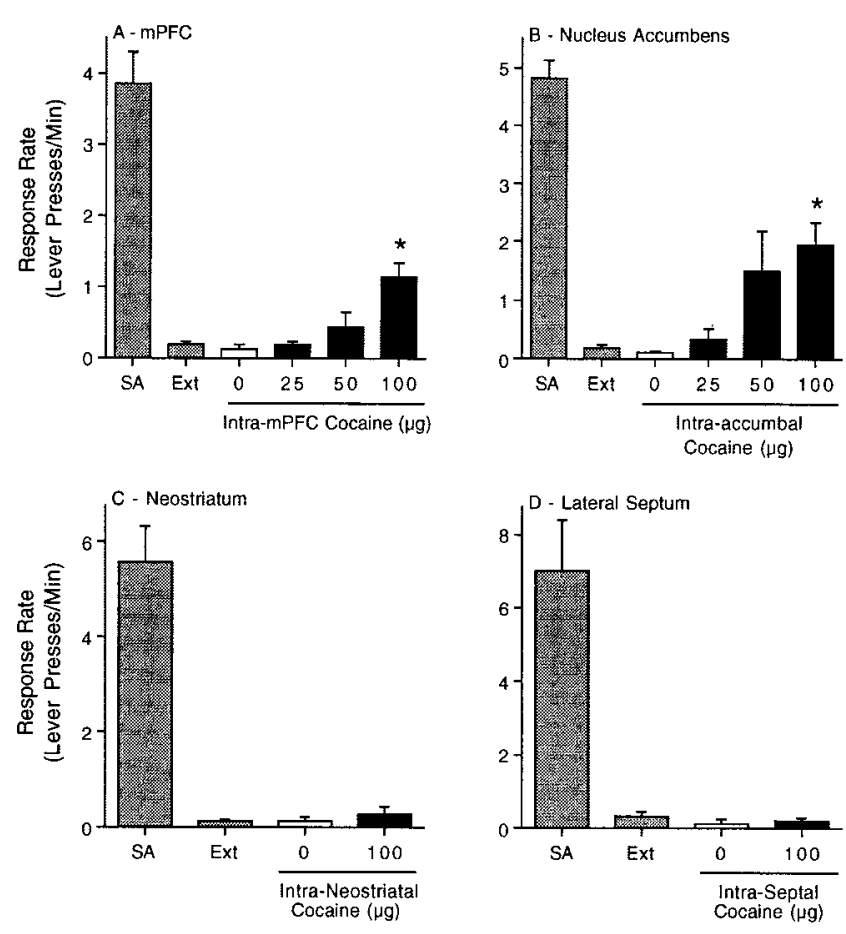

Figure 2. Reinstatement of drug seeking by administration of cocaine into the $\mathrm{mPFC}$ and nucleus accumbens, but not the neostriatum or lateral septum. The data summarized in this figure depict the response rate (Lever presses/Min) during the fifth component of the FI10(FR10) secondorder schedule of reinforcement for the last self-administration $(S A)$ and extinction $(E x t)$ sessions as well as during the reinstatement phases of these experiments. These data indicate that microinjection of $100 \mu \mathrm{g}$ cocaine directly into the mPFC $(A)$ or nucleus accumbens $(B)$ but not into the neostriatum or lateral septum ( $C$ and $D$, respectively) reinstates drug-seeking behavior. The error bars indicate \pm SEM. The asterisks represent significant differences from the vehicle control $(p<0.05$; Tukey's HSD). There were 5-10 rats per treatment.

and extinction sessions as well as the reinstatement phase of the experiment. The response rates for all 10 components of the second-order schedule for the vehicle, amphetamine (50 $\mu \mathrm{g})$, and lidocaine $(100 \mu \mathrm{g})$ treatments are shown in Figure $3 B$. The time course data were analyzed using a mixed-factors ANOVA with repeated measures over component. Although this analysis revealed no significant main effects of treatment $\left(F_{(2,12)}=2.32 ; p<\right.$ $0.14)$, component $\left(F_{(9,108)}=1.00 ; p<0.44\right)$, or a significant treatment $\times$ component interaction $\left(F_{(18,108)}=1.02 ; p<0.45\right)$, subsequent pairwise analyses (Tukey's HSD) showed significant differences between the vehicle and amphetamine treatments during components 2-7. There were five animals per treatment.

\section{Intra-accumbal administration of an AMPA receptor antagonist blocks drug seeking induced by intra-mPFC cocaine}

The data summarized in Figure $4 A$ depict the response rate (lever presses per minute) during the fifth component of the FI10(FR10) second-order schedule of reinforcement for the last self-administration and extinction sessions as well as the reinstatement phase of the experiment. The response rates for all 10 components of the second-order schedule for the vehicle/cocaine and $0.3 \mu \mathrm{g} C N Q X /$ cocaine treatments are shown in Figure $4 B$. The time course data were analyzed using a mixed-factors ANOVA with repeated measures over component. This analysis revealed significant main effects of treatment $\left(F_{(1,14)}=51.05 ; p<\right.$ 

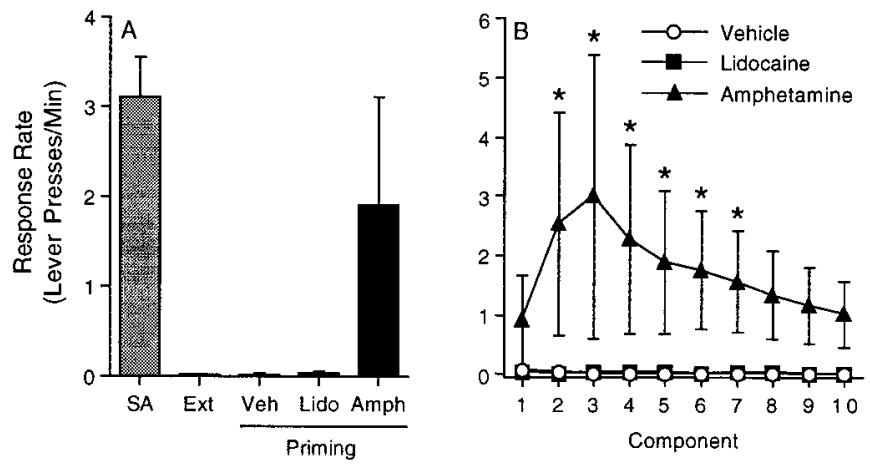

Figure 3. Reinstatement of drug seeking by administration of amphetamine, but not lidocaine, into the mPFC. The data summarized in $A$ depict the response rate (Lever presses/Min) during the fifth component of the FI10(FR10) second-order schedule of reinforcement for the last self-administration and extinction sessions as well as the reinstatement phase of the experiment. The response rates for all 10 components of the second-order schedule for the vehicle, amphetamine $(50 \mu \mathrm{g})$, and lidocaine $(100 \mu \mathrm{g})$ treatments are shown in $B$. The error bars indicate \pm SEM. The asterisks represent significant differences from the vehicle control at that time point ( $p<0.05$; Tukey's HSD). Note that amphetamine significantly increased the response rate relative to the vehicle treatment during components 2-7. There were five animals per treatment.
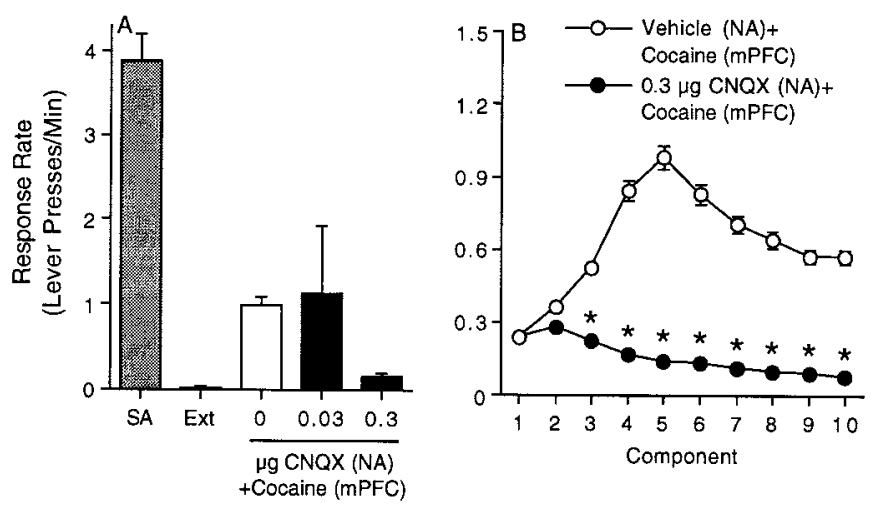

Figure 4. Intra-accumbal administration of the AMPA receptor antagonist $\mathrm{CNQX}$ blocks drug seeking induced by intra-mPFC cocaine. The data summarized in $A$ depict the response rate (Lever presses/Min) during the fifth component of the FI10(FR10) second-order schedule of reinforcement for the last self-administration $(S A)$ and extinction $(E x t)$ sessions as well as the reinstatement phase of the experiment. The error bars indicate \pm SEM. The response rates for all 10 components of the secondorder schedule for the vehicle/cocaine and $0.3 \mu \mathrm{g} C N Q X /$ cocaine treatments are shown in $B$. The error bars indicate \pm SEM. The asterisks represent significant differences from the vehicle control at that time point $(p<0.05$; Tukey's HSD). Note that $0.3 \mu \mathrm{g}$ CNQX significantly decreased the response rate relative to the vehicle control during components 3-10. There were five to nine animals per treatment.

$0.0001)$, component $\left(F_{(9,126)}=5.25 ; p<0.0001\right)$, and a significant treatment $\times$ component interaction $\left(F_{(9,126)}=9.51 ; p<0.0001\right)$. Subsequent pairwise analyses (Tukey's HSD) showed significant differences between the vehicle/cocaine and CNQX/cocaine treatments during components $3-10$. There were five to nine animals per treatment.

\section{Effect of intra-accumbal administration of an NMDA receptor antagonist on drug seeking induced by intra-mPFC cocaine}

The data summarized in Figure $5 A$ depict the response rate (lever presses per minute) during the fifth component of the FI10(FR10)
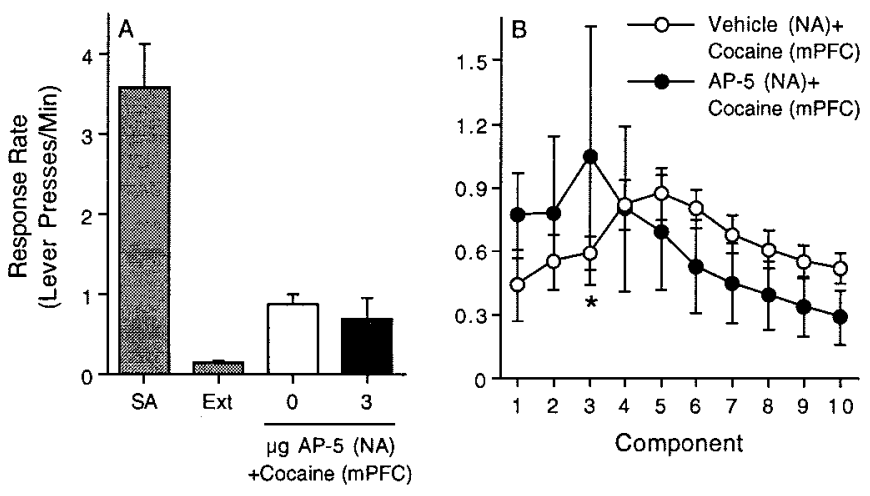

Figure 5. Effect of intra-accumbal administration of the NMDA receptor antagonist AP-5 on drug seeking induced by intra-mPFC cocaine. The data summarized in $A$ depict the response rate (Lever presses/Min) during the fifth component of the FI10(FR10) second-order schedule of reinforcement for the last self-administration $(S A)$ and extinction $(E x t)$ sessions as well as the reinstatement phase of the experiment. The response rates for all 10 components of the second-order schedule for the vehicle/ cocaine and AP-5/cocaine treatments are shown in $B$. The error bars indicate \pm SEM. The asterisk represents a significant difference from the vehicle control at that time point ( $p<0.05$; Tukey's HSD). Note that 3 $\mu \mathrm{g}$ AP-5 significantly increased the response rate relative to the vehicle control treatment during the third component. There were six to eight animals per treatment.

second-order schedule of reinforcement for the last selfadministration and extinction sessions as well as the reinstatement phase of the experiment. The response rates for all 10 components of the second-order schedule for the vehicle/cocaine and AP-5/ cocaine treatments are shown in Figure $5 B$. The time course data were analyzed using a mixed-factors ANOVA with repeated measures over component. This analysis revealed a significant main effect of component $\left(F_{(9,108)}=3.05 ; p<0.003\right)$ and a significant drug treatment $\times$ component interaction $\left(F_{(9,108)}=2.61 ; p<\right.$ 0.009). Subsequent pairwise comparisons (Tukey's HSD) revealed a significant difference between the vehicle and AP-5 treatments at component 3. The effect of intra-accumbal AP-5 on reinstatement induced by intra-mPFC cocaine was variable in that AP-5 had no effect on responding in one-half of the animals but augmented reinstatement in the remaining subjects. There were six to eight animals per treatment.

\section{Reinstatement of drug-seeking behavior by intra-accumbal administration of an NMDA receptor antagonist}

The data summarized in Figure $6 A$ depict the response rate (lever presses per minute) during the fifth component of the FI10(FR10) second-order schedule of reinforcement for the last self-administration and extinction sessions as well as the reinstatement phase of the experiment. The response rates for all 10 components of the second-order schedule for the vehicle and 3 and $30 \mu \mathrm{g}$ AP-5 treatments are shown in Figure $5 B$. The time course data were analyzed using a mixed-factors ANOVA with repeated measures over component. This analysis revealed a marginally significant main effect of treatment $\left(F_{(2,12)}=3.17 ; p<\right.$ $0.078)$, a significant main effect of component $\left(F_{(9,108)}=4.89 ; p<\right.$ $0.0001)$, and a significant drug treatment $\times$ component interaction $\left(F_{(18,108)}=1.88 ; p<0.026\right)$. Subsequent pairwise comparisons (Tukey's HSD) revealed significant differences between the vehicle and $3 \mu \mathrm{g}$ AP-5 treatments during components $1-4$ and significant differences between the vehicle and $30 \mu \mathrm{g}$ AP-5 treat- 

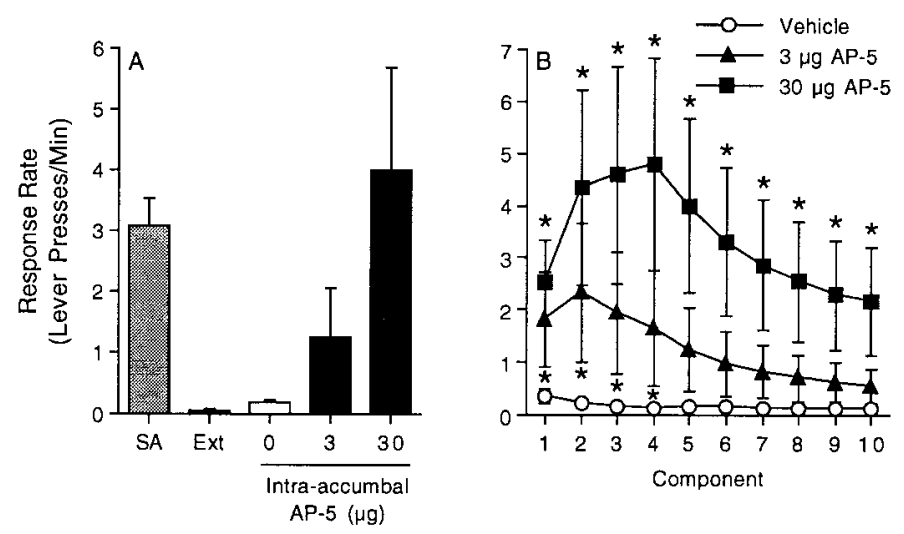

Figure 6. Reinstatement of drug-seeking behavior by intra-accumbal administration of the NMDA receptor antagonist AP-5. The data summarized in $A$ depict the response rate (Lever presses/Min) during the fifth component of the FI10(FR10) second-order schedule of reinforcement for the last self-administration $(S A)$ and extinction $(E x t)$ sessions as well as the reinstatement phase of the experiment. The response rates for all 10 components of the second-order schedule for the vehicle and 3 and 30 $\mu \mathrm{g}$ AP-5 treatments are shown in $B$. The error bars indicate \pm SEM. The asterisks represent significant differences from the vehicle control at that time point $(p<0.05$; Tukey's HSD). Note that $3 \mu \mathrm{g}$ AP-5 increased the response rate during components $1-4$, whereas $30 \mu \mathrm{g}$ increased the response rate at all 10 components, relative to the vehicle control treatment. There were five animals per treatment.

ments during all 10 components. There were five animals per treatment.

\section{Reinstatement of drug-seeking behavior}

The present data indicate that vehicle control injections administered intraperitoneally or directly into the nucleus accumbens, neostriatum, or $\mathrm{mPFC}$ do not result in significant responding during the reinstatement sessions. Because stress can reinstate cocaine-seeking behavior (Erb et al., 1996; Shaham et al., 1998; Martin-Fardon et al., 2000; Shaham et al., 2000), these results indicate that our control manipulations are not sufficiently stressful to engender drug-seeking behavior. Reinstatement of drug seeking after the vehicle injection would also be expected if the light over the cocaine-associated bar had achieved stimulus control. The influence of the cocaine-associated cue light on cocaineinduced reinstatement of drug seeking was assessed by evaluating reinstatement induced by cocaine $(10 \mathrm{mg} / \mathrm{kg}$, i.p. $)$ in the presence or absence of the cocaine-associated cue light. Results indicated that the cue light had no effect on reinstatement in that the cocaine seeking induced by $10 \mathrm{mg} / \mathrm{kg}$ did not significantly differ when the light was present or absent $\left(t_{(8)}=0.28 ; p<\right.$ $0.78)$. The mean \pm SEM response rates for the fifth component of the second-order schedule during the reinstatement phase for the light present and light absent treatments were as follows: present $=1.71 \pm 0.88$; absent $=1.98 \pm 0.35$. These results indicate that the cocaine-associated light cue did not contribute to priming-induced reinstatement under the present training and testing conditions. There were five animals per treatment.

The animals in the current cocaine self-administration experiments underwent a series of extinction and reinstatement sessions that lasted $\sim 20 \mathrm{~d}$. During this period, extinction of the ability of a priming injection to induce drug seeking is a concern. However, in our experience the current training and testing procedures produce robust priming-induced reinstatement of cocaine-seeking behavior that is observed for at least $20 \mathrm{~d}$ after the initial extinction of cocaine self-administration. This is illustrated in a group of animals in which reinstatement induced by 10 $\mathrm{mg} / \mathrm{kg}$ cocaine was assessed after treatments that had no influence on drug-seeking behavior (i.e., the presence or absence of the cue light or saline administration into the mPFC). Drug seeking was stable throughout the reinstatement phase of these experiments. Thus, during the first and last reinstatement sessions, the mean \pm SEM for the fifth component of the secondorder schedule was $2.2 \pm 0.82$ and $1.41 \pm 0.36$, respectively. The extent of reinstatement did not differ between the first and last sessions $\left(t_{(5)}=1.08 ; p<0.33\right)$, and the magnitude of drug seeking in these treatments was consistent across all of the reinstatement sessions. There were six animals included in this analysis.

\section{Inactive lever presses during reinstatement of drug seeking}

Responding on an inactive lever is often used as a measure of nonspecific increases or decreases in lever pressing during the reinstatement phase. With the current training and testing procedures, the rate of inactive lever presses was very low, which decreases the utility of this measure in the determination of nonspecific decreases in operant responding. For example, in the experiment designed to assess the influence of the cocaineassociated light cue on reinstatement, the total number of responses on the inactive lever was very low in both groups (10 $\mathrm{mg} / \mathrm{kg}$ cocaine plus light $=2.4 \pm 2.4 ; 10 \mathrm{mg} / \mathrm{kg}$ cocaine with no light $=1.8 \pm 0.66$; data are presented as the average total number of inactive lever presses per session \pm SEM). These data not only confirm that the number of inactive lever presses is too low to meaningfully assess potential rate-suppressant effects of drugs, but these results also demonstrate that $10 \mathrm{mg} / \mathrm{kg}$ cocaine selectively increased responding only on the active lever (contrast an average of 150.4 total presses on the active lever vs an average of 2.4 total responses on the inactive lever during the reinstatement phase in the $10 \mathrm{mg} / \mathrm{kg}$ cocaine plus light treatment). Similarly, intra-accumbal administration of AP-5 selectively increased responding on the active lever. The results from a representative animal reveal that intra-accumbal AP-5 produced 129 responses on the active lever and 1 response on the inactive lever. Therefore, nonspecific increases in lever pressing are not responsible for the reinstatement of drug seeking induced by cocaine or AP-5. Because the rate of inactive lever pressing during the reinstatement phase was so low under the present conditions, we assessed the effect of glutamate and dopamine antagonists on operant responding maintained by an alternate reinforcer (food), as described in the next section.

\section{Effect of glutamate and dopamine antagonists on food-reinforced operant behavior}

The data from Table 1 represent the average number of lever presses per minute for $1 \mathrm{hr}$ after the intra-accumbal or intra$\mathrm{mPFC}$ microinjection of antagonists or their vehicles. Before the self-administration session, $0.3 \mu \mathrm{g}$ CNQX or 3.0 or $30.0 \mu \mathrm{g}$ AP-5 or their vehicles (1\% DMSO or $0.9 \%$ saline, respectively) were microinjected into the nucleus accumbens. These data were analyzed with a one-way ANOVA, which revealed a significant main effect of treatment $\left(F_{(4,27)}=15.1 ; p<0.0001\right)$. Post hoc analyses revealed a significant difference between the CNQX and DMSO treatments (Tukey's HSD). Also shown in Table 1 are food self-administration data obtained after the microinjection of 30.0 $\mu \mathrm{g}$ flupenthixol or saline into the mPFC. A $t$ test revealed no significant difference between these treatments $\left(t_{(8)}=1.24 ; p<\right.$ $0.25)$. There were $4-10$ animals per treatment. 


\begin{tabular}{|c|c|c|}
\hline Drug or vehicle & $n$ & Lever presses per minut \\
\hline \multicolumn{3}{|l|}{ Nucleus accumbens } \\
\hline Saline & 10 & $23.5(2.5)$ \\
\hline $1 \%$ DMSO & 6 & $22.7(3.5)$ \\
\hline $0.3 \mu \mathrm{g}$ CNQX & 6 & $43.5(2.1)^{*}$ \\
\hline $3 \mu \mathrm{g}$ AP-5 & 6 & $22.1(1.8)$ \\
\hline $30 \mu \mathrm{g}$ AP-5 & 4 & $13.4(1.4)$ \\
\hline \multicolumn{3}{|l|}{$\mathrm{mPFC}$} \\
\hline Saline & 5 & $21.0(4.1)$ \\
\hline $30 \mu \mathrm{g}$ Flupenthixol & 5 & $15.1(2.5)$ \\
\hline
\end{tabular}

The data are represented as the average number of food pellets dispensed per minute $( \pm$ SEM) for $1 \mathrm{hr}$ after the intra-accumbal microinjection. Note that intraaccumbal CNQX produced a significant increase in lever pressing maintained by food. *Significant difference from the $1 \%$ DMSO treatment $(p<0.05$; Tukey's HSD).

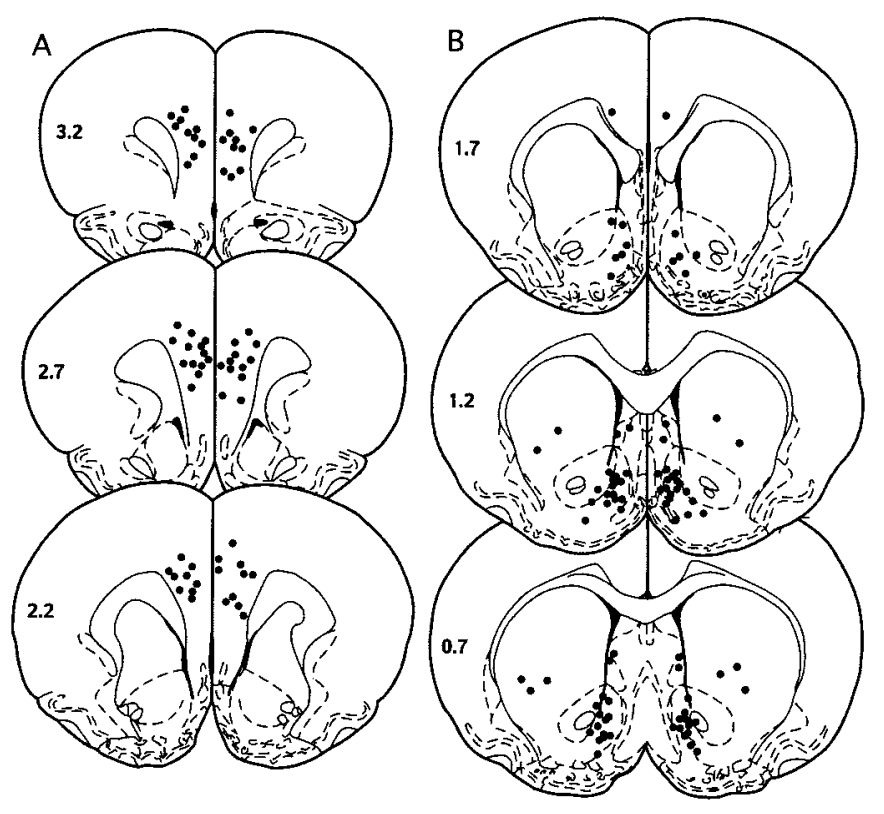

Figure 7. Cannula placements in the mPFC, nucleus accumbens, neostriatum, and lateral septum. The placements in the mPFC included the anterior cingulate and infralimbic and prelimbic cortices $(A)$. The accumbal placements were aimed at the medial nucleus accumbens encompassing the medial portion of the shell and the border between the medial shell and the core. The neostriatal microinjections were all confined to the central-ventral and lateral-ventral regions of this structure. Note that the microinjections in the lateral septum were directly above the microinjections aimed at the nucleus accumbens. None of the drugs administered into the mPFC nucleus accumbens, neostriatum, or lateral septum produced neurotoxicity $(B)$. No excessive mechanical damage caused by the repeated microinjections into any of these brain regions was observed.

\section{Cannula placements in the mPFC, nucleus accumbens, neostriatum, and lateral septum}

The cannula placements in the mPFC, nucleus accumbens, neostriatum, and lateral septum from the experiments outlined in Figures 2-6 and Table 1 are shown in Figure 7. The placements in the mPFC included the anterior cingulate and infralimbic and prelimbic cortices (Fig. 6A). The accumbal placements were aimed at the medial nucleus accumbens encompassing the medial portion of the shell and the border between the medial shell and the core (Fig. $6 B$ ). The microinjections into the neostriatum were confined to the central-ventral and lateral-ventral portions of this structure, whereas the microinjections aimed at the lateral septum were $\sim 2 \mathrm{~mm}$ above the medial nucleus accumbens (Fig. $6 B)$. None of the drugs administered into the mPFC, nucleus accumbens, neostriatum, or lateral septum produced neurotoxicity. No excessive mechanical damage caused by the repeated microinjections into any of these brain regions was observed.

\section{DISCUSSION}

The present results indicate that administration of cocaine into either the $\mathrm{mPFC}$ or the nucleus accumbens reinstated cocaineseeking behavior. Intra-mPFC cocaine reinstated cocaine seeking by increasing AMPA-mediated glutamate transmission in the nucleus accumbens. In contrast, administration of an NMDA antagonist into the nucleus accumbens reinstated cocaine-seeking behavior. Collectively, these data indicate that the glutamatergic pathway from the mPFC to the nucleus accumbens plays an important role in priming-induced reinstatement of cocaine seeking. Moreover, the present results indicate that accumbal AMPA and NMDA receptors have opposing roles in the modulation of cocaine-seeking behavior.

\section{The role of $\mathrm{mPFC}$ dopamine in cocaine-induced reinstatement of drug seeking}

Cocaine blocks the reuptake of dopamine, norepinephrine, and serotonin (Koe, 1976; Heikkila et al., 1979). Although there is some evidence that norepinephrine and serotonin modulate reinstatement of cocaine-seeking behavior (Tran-Nguyen et al., 1999; Erb et al., 2000), an extensive literature of cocaine reinstatement studies have revealed a fundamental role for mesocorticolimbic dopamine systems. Previous research indicates that D2-like receptor agonists administered systemically reinstate cocaine-seeking behavior (Self et al., 1996; De Vries et al., 1999, 2002; Khroyan et al., 2000), whereas D1-like and D2-like receptor antagonists attenuate the reinstatement of cocaine-seeking behavior (Khroyan et al., 2000). These findings, when coupled with the fact that transient pharmacological inhibition of the mPFC prevents cocaine priming-induced reinstatement of drug seeking (McFarland and Kalivas, 2001), suggest that increased dopamine transmission in the mPFC may at least partially mediate priminginduced reinstatement of cocaine seeking. Consistent with this hypothesis, the current results indicate that intra-mPFC administration of a dopamine antagonist blocked reinstatement induced by a systemic cocaine injection. Moreover, microinjection of cocaine directly into the $\mathrm{mPFC}$ reinstated drug-seeking behavior. The reinstatement of drug seeking induced by an intra-mPFC priming injection of cocaine could be caused by the local anesthetic property of this drug. However, the current results indicate that administration of the local anesthetic lidocaine directly into the mPFC failed to reinstate drug-seeking behavior. This result is consistent with previous work demonstrating that the behavioralactivating effects of intra-accumbal cocaine are not attributable to local anesthesia (Delfs et al., 1990). Moreover, the present results indicate that intra-mPFC microinjection of amphetamine, a stimulant that is pharmacologically similar to cocaine but not a local anesthetic, reinstated cocaine seeking. Collectively, these results provide support for the hypothesis that the reinstatement of drug seeking by intra-mPFC cocaine is caused by an increase in dopamine transmission rather than a local anesthetic effect. 
The role of accumbal AMPA receptors in the reinstatement of drug seeking by intra-mPFC cocaine

Recent reports indicate that administration of an AMPA agonist into the nucleus accumbens reinstated cocaine seeking in rats, whereas intra-accumbal administration of an AMPA antagonist impaired reinstatement induced by a systemic cocaine priming injection (Cornish et al., 1999; Cornish and Kalivas, 2000). These findings, coupled with the fact that a major accumbal glutamatergic afferent projection originates in the mPFC (Phillipson and Griffiths, 1985; Berendse et al., 1992; Brog et al., 1993; Wright and Groenewegen, 1995), led us to hypothesize that intra-mPFC microinjections of cocaine may reinstate cocaine seeking by altering glutamate transmission in the nucleus accumbens. Consistent with this hypothesis, the current results indicated that a priming microinjection of cocaine into the $\mathrm{mPFC}$ reinstated cocaine seeking and that this effect was blocked by the microinjection of an AMPA antagonist into the nucleus accumbens. The present results, which suggest that the glutamatergic mPFCaccumbal pathway plays a critical role in cocaine priming-induced drug craving, are also consonant with results obtained with an animal model of cocaine-induced plasticity as well as studies performed in human cocaine addicts. In this regard, enhanced activity in the $\mathrm{mPFC}-$ accumbal glutamatergic pathway acting primarily through accumbal AMPA receptors is linked to the expression of behavioral sensitization to cocaine (Bell and Kalivas, 1996; Pierce et al., 1996, 1997b; Reid and Berger, 1996), which has been suggested as an animal model of the neuronal plasticity underlying cocaine craving (Robinson and Berridge, 1993; De Vries et al., 1998a). The mPFC also has been linked to drug craving in human cocaine addicts. Increased blood flow or glucose metabolism was observed in the prefrontal cortex of cocaine addicts exposed to cues associated with cocaine use (Grant et al., 1996; Childress et al., 1999), with the increased cortical blood flow correlating with self-reports of drug craving (Childress et al., 1999). Collectively, these data demonstrate a striking correspondence between data obtained from human and animal models, suggesting that the glutamatergic mPFC-accumbal pathway plays a critical role in cocaine- and cue-induced craving and the relapse of drug-seeking behavior.

Although the present experiments focused on the regulation of cocaine priming-induced reinstatement by the glutamatergic $\mathrm{mPFC}$-accumbal pathway, our results do not rule out a role for other glutamatergic inputs to the nucleus accumbens in this process. Indeed, the amygdala appears to play a particularly important role in cue-induced relapse of cocaine-seeking behavior (Meil and See, 1997; Tran-Nguyen et al., 1998; Grimm and See, 2000; Weiss et al., 2000), and recent evidence indicates that electrical stimulation of the hippocampus reinstates cocaine seeking (Vorel et al., 2001). These results suggest that multiple nuclei that send glutamatergic projections to the nucleus accumbens contribute to priming- and cue-induced reinstatement of cocaine seeking.

\section{Role of NMDA receptors in the reinstatement of drug-seeking behavior}

Microinjection of NMDA into the nucleus accumbens reinstated cocaine seeking in rats (Cornish et al., 1999). However, NMDA increased responding on an inactive lever, suggesting that the increase in responding on the active lever was attributable, at least in part, to a nonspecific increase in motor activity (Cornish et al., 1999). Consistent with this hypothesis, intra-accumbal administration of an NMDA antagonist had no effect on rein- statement induced by a systemic priming injection of cocaine (Cornish et al., 1999) and had variable effects on reinstatement engendered by intra-mPFC cocaine (present study). In the latter case, however, a subset of subjects showed clear augmentation of cocaine-induced reinstatement, and the current data further demonstrate that microinjection of an NMDA antagonist into the nucleus accumbens dose-dependently reinstated cocaine seeking. Our results are consistent with recent findings indicating that NMDA antagonists appear to have reinforcing properties similar in some respects to cocaine (Carlezon and Wise, 1996; Pierce et al., 1997a) and that the systemic administration of an NMDA antagonist reinstates cocaine seeking (De Vries et al., 1998b). Interestingly, it has been shown that reinstatement induced by cocaine-associated stimuli, but not cocaine itself, is blocked by NMDA antagonists (Bespalov et al., 2000), which suggests a differential role for NMDA receptors in cue- and priminginduced reinstatement of cocaine-seeking behavior.

\section{Role of accumbal dopamine in the reinstatement of drug-seeking behavior}

Although an extensive literature indicates that dopamine transmission in the nucleus accumbens plays a critical role in the maintenance of cocaine self-administration (Hurd et al., 1989; Pettit and Justice, 1989; Maldonado et al., 1993; McGregor and Roberts, 1993; Caine et al., 1995; Wise et al., 1995; Parsons et al., 1996; Bradberry et al., 2000; Czoty et al., 2000), the extent to which accumbal dopamine contributes to the reinstatement of cocaine seeking is unclear. Pretreatment with the nonselective dopamine antagonist fluphenazine had no effect on cocaine seeking induced by systemic cocaine or intra-accumbal AMPA (Cornish and Kalivas, 2000). Moreover, electrical stimulation of the medial forebrain bundle, which includes dopaminergic projections to the nucleus accumbens, does not reinstate cocaine seeking (Vorel et al., 2001). Although these results suggest that dopamine transmission in the nucleus accumbens may play a limited role in cocaine-seeking behavior, intra-accumbal administration of cocaine (present results), dopamine (Cornish and Kalivas, 2000), or a PKA inhibitor (Self et al., 1998) reinstated cocaine seeking. Moreover, activation of the mesolimbic dopamine system with intra-VTA morphine reinstated cocaineseeking behavior (Stewart, 1984). Collectively, these results indicate that although increased dopamine transmission in the nucleus accumbens may be sufficient to reinstate cocaine seeking, accumbal dopamine may not be required for the reinstatement of drug-seeking behavior in all circumstances.

\section{Effect of NMDA and AMPA receptor antagonists on food-maintained operant responding}

To control for the potential rate-suppressing effect of AMPA and NMDA antagonists, we chose doses of these drugs that did not suppress operant responding maintained by a non-drug reinforcer, which suggests that the behavioral effects of CNQX and AP-5 were not caused by general motor impairment. Consistent with previous findings (Maldonado-Irizarry et al., 1995; Kelley and Swanson, 1997; Stratford et al., 1998), our results indicate that intra-accumbal administration of the AMPA receptor antagonist CNQX increased operant responding maintained by food. This effect appears to be selective for food because intraaccumbal microinjection of an AMPA antagonist does not increase water intake, non-ingestive gnawing, or locomotor activity (Stratford et al., 1998). Moreover, intra-accumbal administration of an AMPA antagonist impaired the reinstatement of drug 
seeking induced by a systemic (Cornish and Kalivas, 2000) or intra-mPFC (present results) priming injection of cocaine. The present results also demonstrated that intra-accumbal administration of the NMDA receptor antagonist AP-5 had no effect on food-maintained operant responding but reinstated cocaineseeking behavior. Taken together, these data indicate that accumbal AMPA and NMDA receptors play different and sometimes opposing roles in the various appetitive behaviors processed by the nucleus accumbens.

\section{Conclusions}

The current results indicate that the glutamatergic mPFC-accumbal pathway plays a critical role in priming-induced reinstatement of drug-seeking behavior. Surprisingly, AMPA and NMDA receptors in the nucleus accumbens play opposing roles in this process in that increased AMPA and decreased NMDA receptormediated glutamate transmission both facilitate reinstatement of cocaine seeking. Understanding the anatomical and pharmacological bases of cocaine priming-induced relapse of drug-seeking behavior advances our understanding of the basic mechanisms underlying drug craving. Moreover, the current results could lead to the development of pharmacological therapies based on the manipulation of glutamate transmission in the basal forebrain that may be useful in the prevention of cocaine craving and relapse.

\section{REFERENCES}

Bell K, Kalivas PW (1996) Context-specific cross sensitization between systemic cocaine and intra-accumbens AMPA inf usion in rats. Psychopharmacology 127:377-383.

Berendse HK, Galis DE, Graaf Y, Groenewegen HJ (1992) Topographical organization and relationship with ventral striatal compartments of prefrontal corticostriatal projections in the rat. J Comp Neurol 316:314-367.

Bespalov AY, Zvartau EE, Balster RL, Beardsley PM (2000) Effects of $N$-methyl-D-aspartate receptor antagonists on reinstatement of cocaineseeking behavior by priming injections of cocaine or exposures to cocaine-associated cues in rats. Behav Pharmacol 11:37-44.

Bradberry CW, Barrett-Larimore RL, Jatlow P, Rubino SR (2000) Impact of self-administered cocaine and cocaine cues on extracellular dopamine in mesolimbic and sensorimotor striatum in rhesus monkeys. J Neurosci 20:3874-3883.

Brog JS, Salyapongse A, Deutch AY, Zahm DS (1993) The patterns of afferent innervation of the core and shell in the "accumbens" part of the ventral striatum: immunohistochemical detection of retrogradely transported Fluoro-Gold. J Comp Neurol 338:255-278.

Caine SB, Heinrichs SC, Coffin VL, Koob GF (1995) Effects of the dopamine D1 antagonist SCH 23390 microinjected into the accumbens, amygdala or striatum on cocaine self-administration in the rat. Brain Res 692:47-56.

Carlezon WA, Wise RA (1996) Rewarding actions of phencyclidine and related drugs in nucleus accumbens shell and frontal cortex. J Neurosci 16:3112-3122.

Carroll KM, Rounsaville BJ, Gordon LT, Nich C, Jatlow P, Bisighini RM, Gawin FH (1994) Psychotherapy and pharmacotherapy for ambulatory cocaine abusers. Arch Gen Psychiatry 51:177-187.

Childress AR, Mozley PD, McElgin W, Fitzgerald J, Reivich M, O'Brien CP (1999) Limbic activation during cue-induced cocaine craving. Am J Psychiatry 156:11-18.

Comer SD, Lac ST, Curtis LK, Carroll ME (1993) Effects of buprenorphine and naltrexone on reinstatement of cocaine-reinforced responding in rats. J Pharmacol Exp Ther 267:1470-1477.

Cornish JL, Kalivas PW (2000) Glutamate transmission in the nucleus accumbens mediates relapse in cocaine addiction. $J$ Neurosci 20:RC89(1-5).

Cornish JL, Duffy P, Kalivas PW (1999) A role for nucleus accumbens glutamate transmission in the relapse to cocaine-seeking behavior. Neuroscience 93:1359-1367.

Czoty PW, Justice Jr JB, Howell LL (2000) Cocaine-induced changes in extracellular dopamine determined by microdialysis in awake squirrel monkeys. Psychopharmacology 148:299-306.

Delfs JM, Schreiber L, Kelley AE (1990) Microinjection of cocaine into the nucleus accumbens elicits locomotor activation in the rat. J Neurosci 10:303-310.

De Vries TJ, Schoffelmeer ANM, Binnekade R, Mulder AH, Vander- schuren LJMJ (1998a) Drug-induced reinstatement of heroin- and cocaine-seeking behaviour following long-term extinction is associated with expression of behavioural sensitization. Eur $\mathrm{J}$ Neurosci 10:3565-3571.

De Vries TJ, Schoffelmeer ANM, Binnekade R, Mulder AH, Vanderschuren LJMJ (1998b) MK-801 reinstates drug-seeking behaviour in cocaine-trained rats. NeuroReport 9:637-640.

De Vries TJ, Schoffelmeer ANM, Binnekade R, Vanderschuren LJMJ (1999) Dopaminergic mechanisms mediating the incentive to seek cocaine and heroin after long-term withdrawal of IV drug selfadministration. Psychopharmacology 143:254-260.

De Vries TJ, Schoffelmeer ANM, Binnekade R, Raaso H, Vanderschuren LJMJ (2002) Relapse to cocaine- and heroin-seeking behavior mediated by dopamine D2 receptors is time-dependent and associated with behavioral sensitization. Neuropsychopharmacology 26:18-26.

de Wit H, Stewart J (1981) Reinstatement of cocaine-reinforced responding in the rat. Psychopharmacology 75:134-143.

Erb S, Shaham Y, Stewart J (1996) Stress reinstates cocaine-seeking behavior after prolonged extinction and a drug-free period. Psychopharmacology 128:408-412.

Erb S, Hitchcott PK, Rajabi H, Mueller D, Shaham Y, Stewart J (2000) Alpha-2 adrenergic receptor agonists block stress-induced reinstatement of cocaine seeking. Neuropsychopharmacology 23:138-150.

Gerber GJ, Stretch R (1975) Drug-induced reinstatement of extinguished self-administration behavior in monkeys. Pharmacol Biochem Behav 3:1055-1061.

Goeders NE, Smith JE (1983) Cortical dopaminergic involvement in cocaine reinforcement. Science 221:773-775.

Grant S, London ED, Newlin DB, Villemangne V L, Liu X, Contoreggi C, Phillips RL, Kimes AS, Margolin A (1996) Activation of memory
circuits during cue-elicited cocaine craving. Proc Natl Acad Sci USA 93:12040-12045.

Grimm JW, See RE (2000) Dissociation of primary and secondary reward-relevant limbic nuclei in an animal model of relapse. Neuropsychopharmacology 22:473-479.

Heikkila RE, Cabbat FS, Manzino L, Duvoisin RC (1979) Rotational behavior induced by cocaine analogs in rats with unilateral 6-hydroxydopamine lesions of the substantia nigra: dependence upon dopamine uptake inhibition. J Pharmacol Exp Ther 211:189-194.

Hurd YL, Weiss F, Koob GF, And NE, Ungerstedt U (1989) Cocaine reinforcement and extracellular dopamine overflow in rat nucleus accumbens: an in vivo microdialysis study. Brain Res 498:199-203.

Jaffe JH, Cascella NG, Kumor KM, Sherer MA (1989) Cocaineinduced cocaine craving. Psychopharmacology 97:59-64.

Kelley AE, Swanson CJ (1997) Feeding induced by blockade of AMPA and kainate receptors within the ventral striatum: a microinfusion mapping study. Behav Brain Res 89:107-113.

Khroyan TV, Barrett-Larimore RL, Rowlett JK, Spealman RD (2000) Dopamine D1- and D2-like receptor mechanisms in relapse to cocaineseeking behavior: effects of selective antagonists and agonists. J Pharmacol Exp Ther 294:680-687.

Koe BK (1976) Molecular geometry of inhibitors of the uptake of catecholamines and serotonin in synaptosomal preparations of rat brain. J Pharmacol Exp Ther 199:649-661.

Koob GF, Sanna PP, Bloom FE (1998) Neuroscience of addiction. Neuron 21:467-476.

Maldonado R, Robledo P, Chover AJ, Caine SB, Koob GF (1993) D1 dopamine receptors in the nucleus accumbens modulate cocaine selfadministration in the rat. Pharmacol Biochem Behav 45:239-242.

Maldonado-Irizarry CS, Swanson CJ, Kelley AE (1995) Glutamate receptors in the nucleus accumbens shell control feeding behavior via the lateral hypothalamus. J Neurosci 15:6779-6788.

Martin-Fardon R, Ciccocioppo R, Massi M, Weiss F (2000) Nociceptin prevents stress-induced ethanol- but not cocaine-seeking behavior in rats. NeuroReport 11:1939-1943.

Martin-Iverson MT, Szostak C, Fibiger HC (1986). 6-Hydroxydopamine lesions of the medial prefrontal cortex fail to influence intravenous self-administration of cocaine. Psychopharmacology 88:310-314.

McFarland K, Kalivas PW (2001) The circuitry mediating cocaine-induced reinstatement of drug-seeking behavior. J Neurosci 21:8655-8663.

McGregor A, Roberts DCS (1993) Dopaminergic antagonism within the nucleus accumbens or the amygdala produces differential effects on intravenous cocaine self-administration under fixed and progressive ratio schedules of reinforcement. Brain Res 624:245-252.

McGregor A, Roberts DC (1995) Effect of medial prefrontal cortex injections of SCH 23390 on intravenous cocaine self-administration under both a fixed and progressive ratio schedule of reinforcement. Behav Brain Res 67:75-80.

Meil WM, See RE (1997) Lesions of the basolateral amygdala abolish the ability of drug associated cues to reinstate responding during withdrawal from self-administered cocaine. Behav Brain Res 87:139-148.

Mello NK, Negus SS (1996) Preclinical evaluation of pharmacotherapies for treatment of cocaine and opioid abuse using drug selfadministration procedures. Neuropsychopharmacology 14:375-424. 
Parsons LH, Caine SB, Sokoloff P, Schwartz J-C, Koob GF, Weiss F (1996) Neurochemical evidence that postsynaptic nucleus accumbens D3 receptor stimulation enhances cocaine reinforcement. J Neurochem 67:1078-1089.

Paxinos G, Watson C (1997) The rat brain in stereotaxic coordinates, Ed 3. New York: Academic.

Pettit HO, Justice Jr JB (1989) Dopamine in the nucleus accumbens during cocaine self-administration as studied by in vivo microdialysis. Pharmacol Biochem Behav 34:899-904.

Phillipson OT, Griffiths AC (1985) The topographic order of inputs to the nucleus accumbens in the rat. Neuroscience 16:275-296.

Pierce RC, Bell K, Duffy P, Kalivas PW (1996) Repeated cocaine augments excitatory amino acid transmission in the nucleus accumbens only in rats having developed behavioral sensitization. J Neurosci 16:1550-1560.

Pierce RC, Meil WM, Kalivas PW (1997a) The NMDA antagonist, dizocilpine, enhances cocaine reinforcement without influencing mesoaccumbens dopamine transmission. Psychopharmacology 133:188-195.

Pierce RC, Reeder DC, Hicks J, Morgan ZR, Kalivas PW (1997b) Ibotenic acid lesions of the dorsal prefrontal cortex disrupt the expression of behavioral sensitization to cocaine. Neuroscience 82:1103-1114.

Pulvirenti L, Berrier R, Kreifeldt M, Koob GF (1994) Modulation of locomotor activity by NMDA receptors in the nucleus accumbens core and shell regions of the rat. Brain Res 664:231-236.

Reid MS, Berger SP (1996) Evidence for sensitization of cocaine-induced nucleus accumbens glutamate release. NeuroReport 7:1325-1329.

Robinson TE, Berridge KC (1993) The neural basis of drug craving: an incentive-sensitization theory of addiction. Brain Res Rev 18:247-291.

Self DW, Barnhart WJ, Lehman DA, Nestler EJ (1996) Opposite modulation of cocaine-seeking behavior by D1- and D2-like dopamine receptor agonists. Science 271:1586-1589.

Self DW, Genova LM, Hope BT, Barnhart WJ, Spencer JJ, Nestler EJ (1998) Involvement of cAMP-dependent protein kinase in the nucleus accumbens in cocaine self-administration and relapse of cocaineseeking behavior. J Neurosci 18:1848-1859.

Shaham Y, Erb S, Leung S, Buczek Y, Stewart J (1998) CP-154,526, a selective, non-peptide antagonist of the corticotropin-releasing factor 1 receptor attenuates stress-induced relapse to drug seeking in cocaineand heroin-trained rats. Psychopharmacology 137:184-190.
Shaham Y, Erb S, Stewart J (2000) Stress-induced relapse to heroin and cocaine seeking in rats: a review. Brain Res Rev 33:13-33.

Spealman RD, Barrett-Larimore RL, Rowlett JK, Platt DM, Khroyan TV (1999) Pharmacological and environmental determinants of relapse to cocaine-seeking behavior. Pharmacol Biochem Behav 64:327-336.

Stewart J (1984) Reinstatement of heroin and cocaine self-administration behavior in the rat by intracerebral application of morphine in the ventral tegmental area. Pharmacol Biochem Behav 20:917-923.

Stratford TR, Swanson CJ, Kelley A (1998) Specific changes in food intake elicited by blockade or activation of glutamate receptors in the nucleus accumbens shell. Behav Brain Res 93:43-50.

Tran-Nguyen LT, Fuchs RA, Coffey GP, Baker DA, O'Dell LE, Neisewander JL (1998) Time-dependent changes in cocaine-seeking behavior and extracellular dopamine levels in the amygdala during cocaine withdrawal. Neuropsychopharmacology 19:48-59.

Tran-Nguyen LT, Baker DA, Grote KA, Solano J, Neisewander JL (1999) Serotonin depletion attenuates cocaine-seeking behavior in rats. Psychopharmacology 146:60-66.

Vorel SR, Liu X, Hayes RJ, Spector JA, Gardner EL (2001) Relapse to cocaine-seeking after hippocampal theta burst stimulation. Science 292:1175-1178.

Weiss F, Maldonado-Vlaar CS, Parsons LH, Kerr TM, Smith DL, BenShahar O (2000) Control of cocaine-seeking behavior by drugassociated stimuli in rats: effects on recovery of extinguished operantresponding and extracellular dopamine levels in amygdala and nucleus accumbens. Proc Natl Acad Sci USA 97:4321-4326.

Wise RA, Murray A, Bozarth MA (1990) Bromocriptine selfadministration and bromocriptine-reinstatement of cocaine-trained and heroin-trained lever pressing in rats. Psychopharmacology 100:355-360.

Wise RA, Newton P, Leeb K, Burnette B, Pocock D, Justice Jr JB (1995) Fluctuations in nucleus accumbens dopamine concentration during intravenous cocaine self-administration in rats. Psychopharmacology 120:10-20.

Wright CI, Groenewegen HJ (1995) Patterns of convergence and segregation in the medial nucleus accumbens of the rat: relationships of prefrontal cortical, midline thalamic, and basal amygdaloid afferents. J Comp Neurol 361:383-403. 